\title{
Identification and Characterization of Antibiotic-Producing Actinomycetes Isolates
}

\author{
${ }^{1}$ Meera Kumari, ${ }^{2}$ Bat-Erdene Myagmarjav, \\ ${ }^{1}$ Birendra Prasad and ${ }^{2}$ Madhusudan Choudhary \\ ${ }^{1}$ Department of Botany, Patna University, Patna, India \\ ${ }^{2}$ Department of Biological Sciences, Sam Houston State University, Huntsville, TX 77340, USA
}

Received 2013-01-07, Revised 2013-02-11; Accepted 2013-06-12

\begin{abstract}
Actinomycetes are a gram-positive, filamentous subgroup of bacteria most known for antibiotic production. In fact, most of the antibiotics available today have originated from actinomycetes, namely from the genus Streptomyces. Novel bacteria with antimicrobial activities have been discovered from bacterial screen studies for decades and there is still much more yet to be unearthed. One hundred seventy five strains of actinomycetes were isolated from 38 different soil samples from different locations in Patna, India. Potential antibiotic producers were screened against four test microorganisms (Escherichia coli MTCC 739, Staphylococcus aureus MTCC 96, Streptomyces lividans TK23 MTCC 4 and Candida albicans MTCC 227). The bioassay revealed that about $26 \%$ of actinomycetes isolates were active against at least one of the test microorganism. Characterization of a selected isolate has led to identification of a unique strain of actinomycetes (MP 525) showing broad-spectrum antibacterial and antifungal properties. The strain MP 525 has been morphologically characterized as Streptomyces sp. and deposited at MTCC, Chandigarh, India with accession number 8723. The 16S rRNA gene of the strain Streptomyces sp. US7 MTCC 8723 was sequenced and the DNA sequence was deposited at NCBI, Bethesda (GenBank accession. No. HQ659005). On the basis of $\lambda$ max values of culture filtrates, it has been suggested that the strain might be producing LLE19085-like antibacterial and a flavone glycoside-like antifungal antibiotics, which can be further exploited for industrial and biological applications.
\end{abstract}

Keywords: Actinomycetes, Streptomyces, Antibiotic Production, Phylogenetic Tree

\section{INTRODUCTION}

The phylum Actinobacteria contains several hundred bacterial species that are commonly found in soil, freshwater and marine environments. Some Actinobacteria are also animal and plant pathogens, such as Mycobacterium, Corynebacterium, Nocardia, Rhodococcus and a few species of Streptomyces. These species are gram-positive filamentous bacteria, which produce aerial hyphae and differentiate into chains of spores (Oskay et al., 2004).

Actinobacteria are commonly known as producers of antibiotics and other metabolites (Challis and Hopwood, 2003). In fact, $70-80 \%$ of the commercially available secondary metabolites have been isolated and characterized from several species of actinomycetes (Khanna et al., 2011). These secondary metabolites represent an opulent source of biologically active compounds such as antibiotics, agrochemicals, enzyme, immunosuppressants, antiparasitics and anticancer agents (Berdy, 2005). However, over the last decade, the search for antibiotics and other metabolites in actinomycetes and other microorganisms has become less popular due to the diminishing success of discovering novel strains (Baltz, 2008). As a result, screening for potential chemicals increased but did not yield much success, which is not surprising since Actinobacteria have evolved their capabilities over a billion years (Baltz, 2008). A mathematical model designed to estimate the number of undiscovered

Corresponding Author: Meera Kumari, Department of Botany, Patna University, Patna, India 
antimicrobial agents from the genus Streptomyces predicts that the decline of finding such agents is due to the declining efforts in screening more microorganisms and not due to a lesser number of undiscovered antimicrobial agents (Watve et al., 2001) and thus, the search for microorganisms and new antibiotics has gained importance. For example, it was discovered in Egypt that a strain of actinomycetes, Streptomyces antibioticus AZ-Z710, produced a strong antifungal antibiotics (Atta, 2010). Furthermore, there is an active search in Turkey for an antibacterial agent, producing Streptomyces sp. that can fight antibiotic resistant bacteria (Ceylan et al., 2008) and in China, a new strain of Streptomyces was discovered that kills certain pathogenic fungi (Jiang et al., 2007). Thus, it is anticipated that the isolation and characterization of actinomycetes from different environments can be useful in the discovery of novel strains as well as antibiotics.

The goal of the present study was to isolate actinomycetes from soils from different localities in Patna, India and to screen for potential antibiotic producers from varied environments. After an initial screen for antimicrobial activity, isolates were then morphologically characterized using the parameters described in Bergey's Manual of Determinative Bacteriology (Holt, 1994). To identify the strain, 16S rRNA gene from the newly isolated strain was compared against the NCBI database for closely related 16S rRNA gene sequences. Phylogenetic analysis confirmed the taxonomic status of the new strain as Streptomyces and the organism was classified as Streptomyces sp. US7 MTCC 8723.

\section{MATERIALS AND METHODS}

\subsection{Isolation of Strains and Antibiotics}

Single colonies of actinomycetes were isolated by serial dilution and spread-plate method using Starch Casein Agar (SCA) Medium (1 L solution of $10.0 \mathrm{~g}$ soluble starch; $0.3 \mathrm{~g}$ casein; $2.0 \mathrm{~g} \mathrm{KNO}_{3} ; 2.0 \mathrm{~g} \mathrm{NaCl} ; 2.0$ $\mathrm{g} \mathrm{K}_{2} \mathrm{HPO}_{4}$; traces of $\mathrm{MgSO}_{4} .7 \mathrm{H}_{2} \mathrm{O} ; \mathrm{CaCO}_{3} ; \mathrm{FeSO}_{4} .7 \mathrm{H}_{2} \mathrm{O}$ and $1.5 \mathrm{~g}$ agar, $\mathrm{pH} 6.8 \pm 0.2)$. Soil samples (0.1 gram) were suspended in $9.9 \mathrm{ml}$ normal saline $(0.87 \% \mathrm{NaCl}$, $\mathrm{w} / \mathrm{v}$ ) and serially diluted. $0.1 \mathrm{~mL}$ of inoculums from desired dilution was spread onto sterile SCA agar plate. After incubation at $35 \pm 1{ }^{\circ} \mathrm{C}$ for 3-4 days, rough and chalky colonies were further streaked out onto new plates. The pure cultures were then transferred to SCA slants for further storage.

Screening of single colonies for antimicrobial activity was performed by cross streak method (Waksman and Lechevalier, 1962) using four test microorganisms (Streptomyces lividans TK23 MTCC4, Staphylococcus aureus MTCC 96, Escherichia coli MTCC 739 and Candida albicans MTCC 227). All test microorganisms were procured from Microbial Type Culture Collection (MTCC) and GeneBank, Institute of Microbial Technology (IMTECH), Chandigarh, India. The isolates were characterized for taxonomic identification based on the parameters described in Bergey's Manual of Determinative Bacteriology (Holt, 1994). Furthermore, the selected strains were stored in $20 \%$ glycerol, at $20^{\circ} \mathrm{C}$, in cryovials, as laboratory stock.

\subsection{Phylogenetics Analysis}

The 16S rRNA gene was amplified from Streptomyces sp. US7 MTCC 8723 strain and the subsequent PCR product was sequenced. The sequence was deposited at NCBI, Bethesda. The 16S rRNA gene sequences of closely related taxa were retrieved from the GeneBank database using BLASTN (Altschul et al., 1997). The MEGA 4.1 software was used for construction of phylogenetic trees that are optimal according to the Neighbor-Joining (NJ) method (Tamura et al., 2007).

\subsection{Preparing Culture Filtrate}

About $10^{6}$ spores of the strain were inoculated in a $250 \mathrm{~mL}$ capacity conical flask containing $60 \mathrm{~mL}$ Starch Casein Broth (SCB) media. All inoculated cultures were incubated within a stationary incubator at $35 \pm 1^{\circ} \mathrm{C}$ for 7 , $14,21,30$ and 60 days. The broth cultures were then filtrated by suction pump on preweighed Whatman filter paper no. 1 . The resulting filtrates were centrifuged at $5,000 \times \mathrm{g}$ for $15 \mathrm{~min}$ and supernatant was further characterized for antimicrobial activity.

\subsection{Optimization of Condition for Antibiotic Production}

To optimize the conditions for antibiotic production, the selected strain was grown in eight different media, Glycerol Asparagine Broth (GAB), Starch Casein Broth (GSB), Yeast Extract Malt Extract Broth (YMB), Czapex Dox Broth (CDB), Nutrient Broth (NB), Oat Meal Broth (OMB), Starch Broth (SB) and Soyabean Meal Broth (SMB) as well as at different $\mathrm{pH}$ ranges (5.0-10.0) and different temperature $\left(25,30,35,42\right.$ and $\left.50^{\circ} \mathrm{C}\right)$.

\subsection{Estimation of Dry Weight}

Liquid grown mycelia were harvested and dried (at $90^{\circ} \mathrm{C}$ for $24 \mathrm{~h}$ ) on preweighed Whatman filter paper no. 1 with the help of suction pump. Harvested mycelia were dried in the oven at $80^{\circ} \mathrm{C}$ for $24 \mathrm{~h}$. The difference between the final and initial weight provided the dry weight of mycelia. 


\subsection{Protein Quantification}

Protein amounts in the samples were estimated by using the Lowry et al. (1951) method. Bovine Serum Albumin (BSA) is used as standard.

\subsection{Antibiotic Producing Potential}

The antibiotic producing potential of the selected strain was determined by well diffusion method on an agar plate. The diameter of the zone of complete inhibition was measured to the nearest millimeter. Test organisms used for bioassay were Gram-positive bacteria (Streptomyces lividans TK23 MTCC4, Staphylococcus aureus MTCC96) and Gram-negative bacteria (Escherichia coli MTCC739) and a fungus (Candida albicans MTCC227).

\subsection{Spectrophotometer Analysis of Culture Filtrate}

Different bioactive compounds have different absorbance spectra in UV and visible light that enable the characterization of secondary metabolites. $\lambda$ max of secondary metabolites was determined by spectrophotometer (HITACHI-3210). The culture filtrates were scanned over a range of wavelength (200-900 nm) against Starch Casein Broth (SCB) as a reference. On the basis of the scanning graph, $\lambda$ max was determined.

\section{RESULTS}

\subsection{Antibiotic production in Different Growth Media at Varying pHs and Temperatures}

Antibiotic activity is defined and measured in terms of its ability to inhibit microbial growth of bacteria, fungi and protozoa (Lancini et al., 1995). Screening of the isolates for antimicrobial properties revealed that about $33 \%$ of actinomycetes isolates in the present study were active against at least one of the four test microorganisms (Streptomyces lividans TK23 MTCC4, Staphylococcus aureus MTCC96, Escherichia coli MTCC739 and Candida albicans MTCC227). Of the total, 12 isolates were found to be efficient antimicrobial metabolites producers. One isolate, MP 525, was able to inhibit the growth of all four test organisms ( $S$. lividans, S. aureus, E. coli) and C. albicans.

The level of antibiotic production in different growth media was listed in Table 1. Results revealed that Starch Casein Broth (SCB) was found to be the most suitable media for antibiotic production. Nutrient Broth (NB), Soybean meal broth (SNB) and Oat Meal Broth (OMB) also favored the production of antibiotics. Yeast and Malt extract Broth (YMB) and Starch Broth (SB) media showed moderate level of antibiotic production. In contrast, Glycerol Asparagine Broth (GAB) and Czapex-Dox Broth (CDB) media were able to produce much less antibiotics.

In addition, antibiotic yield varies at different $\mathrm{pH}$ and temperatures as shown in Table $\mathbf{2}$ and $\mathbf{3}$, respectively. The maximum antibiotic production was observed in the cultures grown at pH 7.0 (Table 2) as well as at $35^{\circ} \mathrm{C}$ temperature (Table 3), No antibiotic production was detected at $50^{\circ} \mathrm{C}$. Zone of inhibitions were small at 30 and $42^{\circ} \mathrm{C}$ and even smaller at $25^{\circ} \mathrm{C}$ (Table 3). Antibiotic production was not detected in 7-day-old culture filtrate, but was noticed after 14 days of incubation. It showed maximum antibiotic production in 30-day-old culture filtrates, which remained constant at stationary phase. Streptomyces sp. US7 MTCC8723 showed significant antagonistic activities against gram-positive bacteria and fungi.

Table 1. Production of antibiotics by actinomycete strain MP525 in different media, shown by the zone diameter $(\mathrm{mm})$ of inhibition against each of the test organism

\begin{tabular}{|c|c|c|c|c|}
\hline Media & $\begin{array}{l}\text { Streptomyces } \\
\text { lividans } \\
\text { MTCC4 }\end{array}$ & $\begin{array}{l}\text { Staphylococcus } \\
\text { aureus } \\
\text { MTCC96 }\end{array}$ & $\begin{array}{l}\text { Escherichia } \\
\text { coli } \\
\text { MTCC739 }\end{array}$ & $\begin{array}{l}\text { Candida } \\
\text { albicans } \\
\text { MTCC227 }\end{array}$ \\
\hline$\overline{\mathrm{GAB}}$ & 1 & 2 & 3 & 1 \\
\hline $\mathrm{SCB}$ & 10 & 20 & 20 & 24 \\
\hline YEMEB & 4 & 7 & 6 & 4 \\
\hline $\mathrm{CzDB}$ & 0 & 0 & 2 & 2 \\
\hline NB & 9 & 13 & 12 & 8 \\
\hline OMB & 8 & 12 & 12 & 8 \\
\hline SB & 5 & 8 & 7 & 5 \\
\hline SMB & 9 & 10 & 12 & 8 \\
\hline
\end{tabular}

Table 2. Production of antibiotic by actinomycete strain MP525 at different $\mathrm{pH}$, shown by the zone diameter $(\mathrm{mm})$ of inhibition against each of the test organism

\begin{tabular}{|c|c|c|c|c|}
\hline$\underline{\mathrm{pH}}$ & $\begin{array}{l}\text { Streptomyces } \\
\text { lividans } \\
\text { MTCC4 }\end{array}$ & $\begin{array}{l}\text { Staphylococcus } \\
\text { aureus } \\
\text { MTCC96 }\end{array}$ & $\begin{array}{l}\text { Escherichia } \\
\text { coli } \\
\text { MTCC739 }\end{array}$ & $\begin{array}{l}\text { Candida } \\
\text { albicans } \\
\text { MTCC227 } \\
\end{array}$ \\
\hline 5 & 10 & 8 & 8 & 3 \\
\hline 6 & 18 & 18 & 17 & 7 \\
\hline 7 & 20 & 20 & 22 & 8 \\
\hline 8 & 19 & 19 & 17 & 7 \\
\hline 9 & 15 & 14 & 14 & 6 \\
\hline 10 & 12 & 12 & 10 & 4 \\
\hline
\end{tabular}

Table 3. Production of antibiotics by actinomycete strain MP525 at different temperatures, shown by the zone diameter $(\mathrm{mm})$ of inhibition against each of the test organism

\begin{tabular}{lcccr}
\hline & $\begin{array}{l}\text { Streptomyces } \\
\text { lividans }\end{array}$ & $\begin{array}{l}\text { Staphylococcus } \\
\text { aureus }\end{array}$ & $\begin{array}{l}\text { Escherichia } \\
\text { coli } \\
\text { MTCandida }\end{array}$ & $\begin{array}{l}\text { Calbicans } \\
\text { ald }\end{array}$ \\
MTC & MTCC4 & MTCC66 & MTCC227 \\
\hline $25^{\circ} \mathrm{C}$ & 2 & 1 & 2 & 3 \\
$30^{\circ} \mathrm{C}$ & 6 & 12 & 14 & 16 \\
$35^{\circ} \mathrm{C}$ & 10 & 20 & 20 & 24 \\
$42^{\circ} \mathrm{C}$ & 8 & 15 & 15 & 20 \\
$50^{\circ} \mathrm{C}$ & 0 & 0 & 0 & 0 \\
\hline
\end{tabular}


As shown in Fig. 1, spore germination was observed within $24 \mathrm{~h}$ of growth and there was remarkable increase in dry weight up to 14 days of incubation. Growth patterns between 14 and 21 days were found to be very even with slight increase in the dry weight of the mycelia. The exponential phase lasted for up to 21 days before reaching stationary phase. The strain showed a significant increase in protein yield from 7 days onwards with a maximum of $560 \mu \mathrm{g} \mathrm{mL}^{-1}$ after 60 days of growth.

\subsection{Characteristic Absorption Spectra}

Absorption spectral analysis of bacterial culture filtrates predicts the nature of the metabolites as an indicator of the specific bacterial species. In this investigation, the absorption spectrum of the culture filtrate of Streptomyces sp. US7 MTCC 8723 displayed two major peaks, one at $345 \mathrm{~nm}$ and the other at $390 \mathrm{~nm}$, as shown in Fig. 2. An increasing trend in the absorbance (O.D) values was observed in different day culture filtrates (up to 30 days of incubation) and a decrease in the absorbance value was observed thereafter.

\subsection{Phylogenetic Analysis of $16 \mathrm{~S}$ Ribosomal RNA Genes and New Strain Identification}

On the basis of morphological, physiological and biochemical characteristics, according to the Bergey's Manual of Determinative Bacteriology (Holt, 1994), MP 525 was identified as Streptomyces sp. US7 and deposited at Microbial Type Culture Collection and GeneBank, IMTECH, Chandigarh, India, with accession number MTCC 8723. The 16S rRNA gene sequence of the strain Streptomyces sp. US7 MTCC 8723 was deposited at NCBI, with a GenBank accession No. HQ659005. The 16S rRNA gene sequences from strains closely related to Streptomyces sp. US7 MTCC 8723 were retrieved from the GeneBank database using BLASTN (Altschul et al., 1997). The Phylogenetic tree shown in Fig. 3 further confirmed that the newly identified strain belongs to the Streptomyces sp. In conclusion, the newly isolated strain Streptomyces sp. US7 MTCC8723 showed broad antimicrobial spectra as it inhibited Gram-positive bacteria, Gram-negative bacteria as well as fungi. These significant results make the strain suitable for further investigation and industrial exploitation.

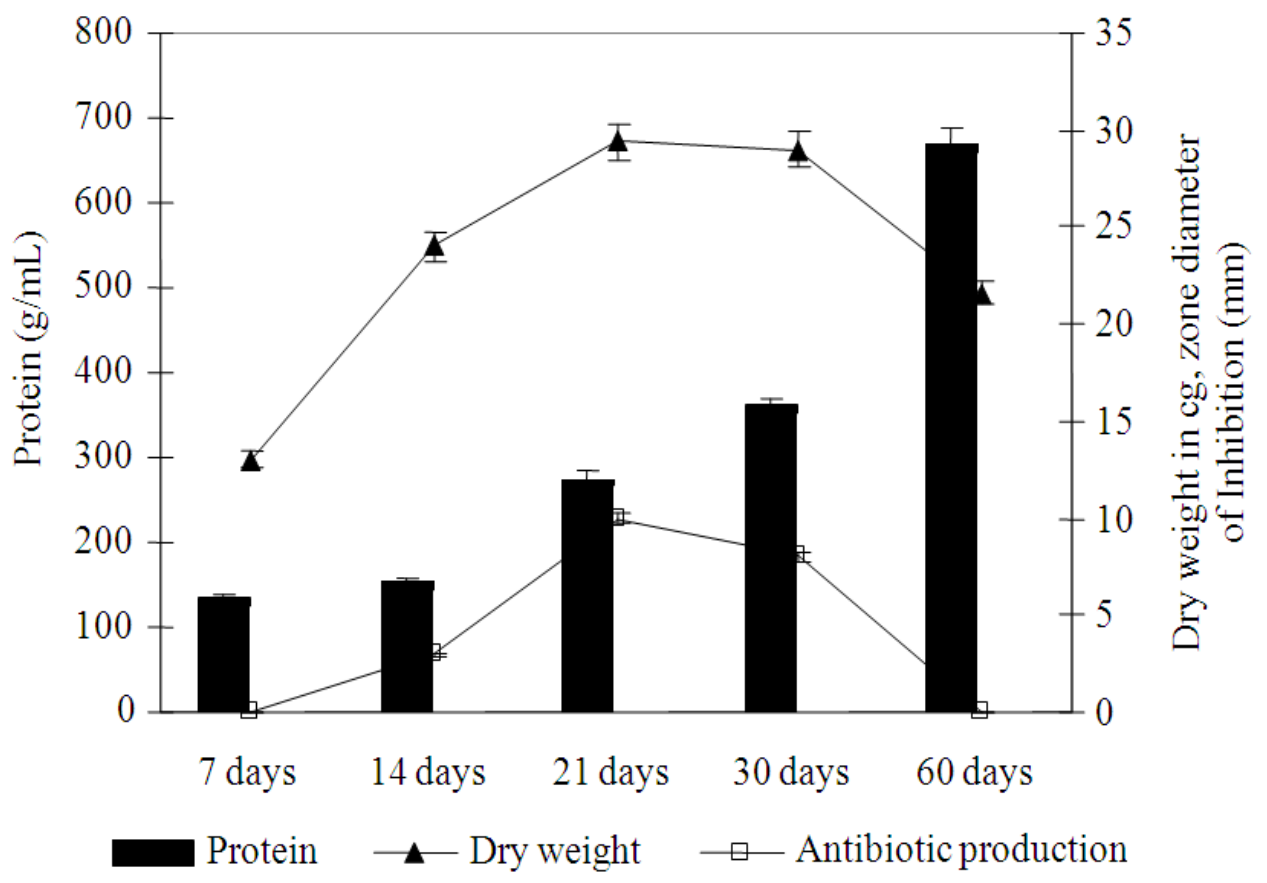

Fig. 1. Time course showing relationship between dry weight, protein and antibiotic production by Streptomyces sp. US7 MTCC 8723 
Meera Kumari et al. / American Journal of Microbiology 4 (1): 24-31, 2013

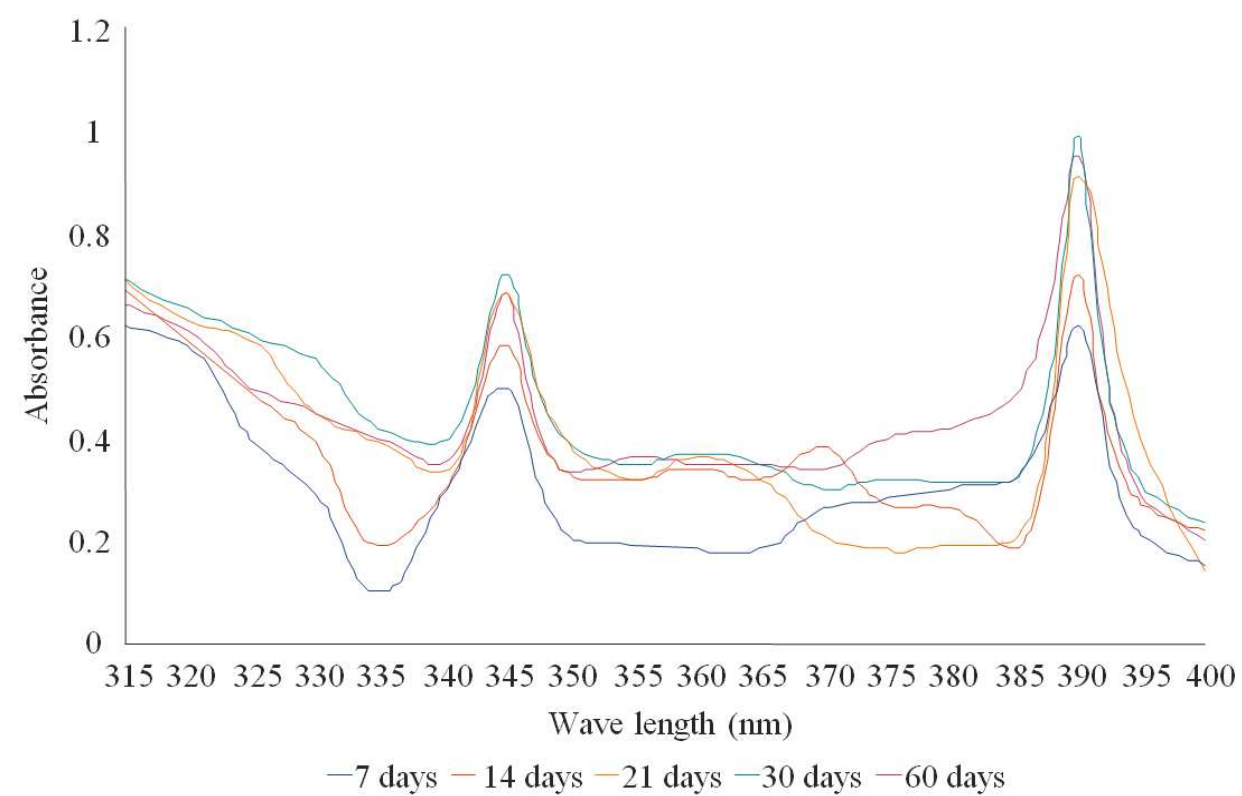

Fig. 2. Absorption spectra of different days old culture filtrates of Streptomyces sp. US7 MTCC 8723

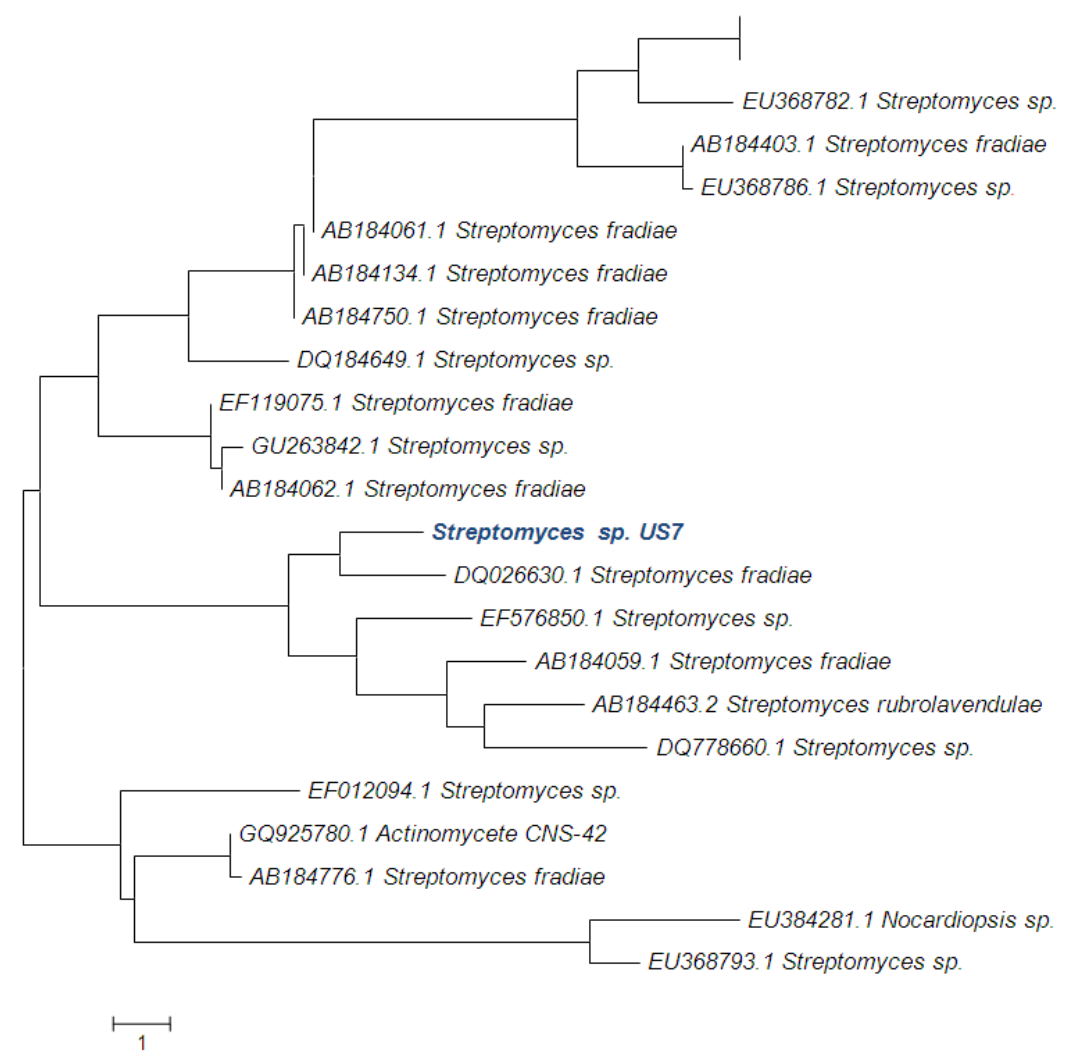

Fig. 3. Phylogenetic tree showing the evolutionary relationship of Streptomyces sp. US7 MTCC8723 with the other 22 taxa 


\section{DISCUSSION}

A total of 175 strains of actinomycetes were isolated from 38 different soil samples collected from different locations of Patna, India. These sites represented heterogeneous environments. In this study, the methods used for isolation of actinomycete strains were similar to methods that have been employed in earlier studies (Williams and Wellington, 1982). The number of bacterial colonies was highest on the SCA medium, which is known as the optimal growth media for isolation of actinomycetes (Hsu and Lockwood, 1975).

Absorption spectral analysis of bacterial culture filtrates predicts the nature of the metabolites as an indicator of the specific bacterial species. In this investigation, the absorption spectrum of the culture filtrate of Streptomyces sp. US7 MTCC 8723 displayed two major peaks, one at $345 \mathrm{~nm}$ and the other at $390 \mathrm{~nm}$, as shown in Fig. 2. Similar observation has also been reported with Streptomyces coelicolor, which produces two antibiotics, a blue colored actinorhodin (ACT) and a red colored undecylprodigiosin (Ryu et al., 2006). It has also reported that the actinomycetes often produce two or more antibiotics simultaneously having different spectral peaks (Krassilnikov, 1981). The first peak (345 nm) of Streptomyces sp. US7 MTCC 8723 with $\lambda \max$ at $347 \mathrm{~nm}$ was most likely a flavone glycoside-like antifungal compound (Jensen et al., 1998). The second peak was at $385 \mathrm{~nm}$ which is the $\lambda \max$ of antibiotic LL-E 19085 beta and gamma (Carter et al., 1992). It has also been observed that, in Streptomyces sp. US7 MTCC8723, the absorbance values of metabolites increased for up to 30 days of incubation and then decreased thereafter. This may be due to feedback inhibition by secondary metabolites (Zahn et al., 2001).

Strains of Streptomyces sp. have the exceptional ability to produce a broad range of low molecular weight compounds of antibacterial and antifungal properties (Hodgson, 2000; Watve et al., 2001; Fulgueira et al., 2004). Environmental factors, such as carbon and nitrogen sources, oxygen tension, temperature, $\mathrm{pH}$ and method of cultivation can affect the timing and extent of production of antibiotics and other secondary metabolites (Martin and Demain, 1980; Iwai and Omura, 1982; Bhattacharyya et al., 1998) as similar to our study. Moreover, in this study Streptomyces sp. US7 MTCC 8723 produced the maximum antibiotic at about neutral $\mathrm{pH}$ and at $35 \pm 1^{\circ} \mathrm{C}$, consistent with previous findings. For example, Streptomyces rochei AK 39 also exhibited optimal results against dermatophytes when grown on
SCA medium with $\mathrm{pH} \quad 7$ and temperature $37^{\circ} \mathrm{C}$ (Augustine et al., 2005).

The growth profile, closely coupled with the metabolic capacities of the producing organism, greatly influences the biosynthesis of antibiotics. For example, nutrient limitation in Streptomyces has been shown to trigger differentiation and induction of bacterial morphology and secondary metabolism (Brana and Demain, 1988). Also, it has been suggested by Augustine et al. (2005) that the maximum production of metabolites occurs in the late log phase and remains constant during the stationary phase. Streptomyces sp. US7 MTCC 8723 similarly showed an increase in biomass up to 21 days of incubation (late log phase). Maximum yield of antimicrobial metabolites was observed in the late log phase and it remained steady during the stationary phase (up to 30 days) indicating the direct relationship between growth rate and metabolite production.

The major processes associated with the phase of secondary metabolism in Streptomyces thermoviolaceus consists of antibiotic synthesis and protein secretion. These occur at a time when nutrients in growth media are still in excess and growth is still continuing (James and Edwards, 1989). It has also been suggested that the protein secretion is invariably linked to the production of graniticin antibiotic in Streptomyces thermoviolaceus. Streptomyces sp. US7 MTCC 8723 showed continuous increase of protein in broth up to 60 days of incubation whereas decline in antibiotic production during 30 to 60 days of incubation.

\section{CONCLUSION}

The newly isolated strain Streptomyces sp. US7 MTCC8723 showed broad antimicrobial spectra as it inhibited Gram-positive bacteria, Gram-negative bacteria as well as fungi. These significant results make the strain suitable for further investigation and industrial exploitation.

\section{REFERENCES}

Altschul, S.F., T.L. Madden, A.A. Schaffer, J. Zhang and Z. Zhang et al., 1997. Gapped BLAST and PSIBLAST: A new generation of protein database search programs. Nucl. Acids Res., 25: 3389-3402. PMID: 9254694

Atta, H.M., 2010. Production, purification, physicochemical characteristics and biological activities of antifungal antibiotic produced by streptomyces antibioticus, AZ-Z710. Am. Eurasian J. Scientific Res., 5: 39-49. 
Augustine, S.K., S.P. Bhavsar and B.P. Kapadnis, 2005. Production of a growth dependent metabolite active against dermatophytes by Streptomyces rochei AK 39. Indian J. Med. Res., 121: 164-170. PMID: 15802758

Baltz, R.H., 2008. Renaissance in antibacterial discovery from actinomycetes. Curr. Opin. Pharmacol., 8: 557563. PMID: 18524678

Berdy, J., 2005. Bioactive microbial metabolites: A personal view. J. Antibiot, 58: 1-26. DOI: 10.1038/ja.2005.1

Bhattacharyya, B.K., S.C. Pal and S.K. Sen, 1998. Antibiotic production by Streptomyces hygroscopicus D1.5: Cultural effect. Revista Microbiol., 29. DOI: 10.1590/S000137141998000300003

Brana, A.F. and A.L. Demain, 1988. Nitrogen Source Control of Antibiotic Biosynthesis in Actinomycetes. In: Nitrogen Source Control of Microbial Processes, Esquivel, S.S. (Eds.), CRC Press, Boce Raton, Florida, ISBN-10: 0849362237, pp: 99-119.

Carter, G.T., J.J. Goodman and D.P. Labeda, 1992. Antibiotic LL-E19085. United States Patent 5096907.

Ceylan, O., G. Okmen and A. Ugur, 2008. Isolation of soil Streptomyces as source antibiotics active against antibiotic-resistant bacteria. Eurasian J. BioSci., 2: 73-82.

Challis, G.L. and D.A. Hopwood, 2003. Synergy and contingency as driving forces for the evolution of multiple secondary metabolite production by Streptomyces species. Proc. Natl. Acad. Sci. US., 100: 14516-14555. DOI: 10.1073/pnas. 1934677100

Fulgueira, C.L., S.L. Amiglot and C. Magni, 2004. Growth inhibition of toxigenic fungi by a proteinaceous compound from Streptomyces sp. C/33-6. C/33-6. Curr. Microbiol., 48: 135-139. DOI: 10.1007/s00284-003-4128-z

Hodgson, D.A., 2000. Primary metabolism and its control in streptomycetes: A most unusual group of bacteria. Adv. Microbiol. Physiol., 42: 47-238. DOI: 10.1016/S0065-2911(00)42003-5

Holt, J.G., 1994. Bergey's Manual of Determinative Bacteriology. 9th Edn., Lippincott Williams and Wilkins, Baltimore, ISBN-10: 0683006037, pp: 787.

Hsu, S.C. and J.L. Lockwood, 1975. Powdered chitin agar as a selective medium for enumeration of actinomycetes in water and soil. Applied Microbiol., 29: 422-426.
Iwai, Y. and S. Omura, 1982. Culture conditions for screening of new antibiotics. J. Antibiot., 35: 123141. PMID: 7042669

James, P.D. and C. Edwards, 1989. The effects of temperature on growth and production of the antibiotic granaticin by a thermotolerant streptomycete.. J. Gen. Microbiol., 135: 1997-2003. PMID: 2575655

Jensen, P.R., K.M. Jenkins, D. Porter and W. Fenical, 1998. Evidence that a new antibiotic flavone glycoside chemically defends the sea grass Thalassia testudinum against Zoosporic fungi. Applied Environ. Microbiol., 64: 1490-1496. PMID: 16349549

Jiang, Y., L.L. Huang, C.Q. Chen, H.P. Qiao and Z.S. Kang, 2007. Screen, identification and optimized fermentation condition of an actinomycete strain against pathogenic fungus Fulvia fulva. Wei Sheng Wu Xue Bao., 47: 622-627. PMID: 17944361

Khanna, M., R. Solanki and R. Lal, 2011. Selective isolation of rare actinomycetes producing novel antimicrobial compounds. Int. J. Adv. Biotechnol. Res., 2: 357-375.

Krassilnikov, N.A., 1981. Culturing Properties. In: Ray Fungi: Higher Forms, APC, (Eds.), Amerind Publishing Co., Moscow, pp: 87-112.

Lancini, G., F. Parenti and G.G. Gallo, 1995. Antibiotics-A Multidisciplinary Approach. 1st Edn., Springer, New York, ISBN-10: 0306449242, pp: 278.

Lowry, O.H., N.J. Rosenbrough, A.L. Farr and R.J. Randell, 1951. Protein measurement with the folin phenol reagent. J. Biol. Chem., 193: 265-275. PMID: 14907713

Martin, J.F. and A.L. Demain, 1980. Control of antibiotic biosynthesis. Microbiol. Rev., 44: 230254. PMID: 6991900

Oskay, M., U.A. Tamer and C. Azeri, 2004. Antibacterial activity of some actinomycetes isolated from farming soils of Turkey. Afr. J. Biotechnol., 3: 441-446.

Ryu, Y.G., M.J. Butter, K.F. Chater and K.J. Lee, 2006. Engineering of primary carbohydrate metabolism for increase production of Actinorhodin in Streptomyces coelicolor. Applied Environ. Microbiol., 72: 71327139. PMID: 16950896

Tamura, K., J. Dudley, M. Nei and S. Kumar, 2007. MEGA4: Molecular Evolutionary Genetics Analysis (MEGA) software version 4.0. Mol. Biol. Evol., 24: 1596-1599. PMID: 17488738 
Waksman, S.A. and H.A. Lechevalier, 1962. The Actinomycetes. The Williams and Willkins Co., Baltimore, MD. ASIN: B000L2SYJG, pp: 20.

Watve, M.G., R. Tickoo, M.M. Jog and B.D. Bhole, 2001. How many antibiotics are produced by the genus Streptomyces. Arch. Microbiol., 176: 386390. PMID: 11702082

Williams, S.T. and E.M.H. Wellington, 1982. Principles and Problems of Selective Isolation of Microbes. In: Bioactive Metabolic Products: Search and Discovery, Bu'lock J.D., (Ed.), Academic Press, London, ISBN-10: 0121407500, pp: 9-26.
Zahn, J.A., R.E. Higgs and M.D. Hilton, 2001. Use of direct-infusion electrospray mass spectrometry to guide empirical development of improved conditions for expression of secondary metabolites from Actinomycetes. Applied Environ. Microbiol., 67: 377-386. PMID: 11133469 